\title{
Novas directrizes na educação
}

\author{
João Arruda
}

I - Não pude conseguir uma nota estatistica, informando-me sobre o numero de bachareis em Direito e doutores em Medicina formados o anno passado no Brasil, embora houvesse recorrido ao Reitor da Universidade de S. Paulo, o Exmo. Snr. Professor Reynaldo Porchat, figura proeminente na direcção do ensino em todo o paiz. E' entretanto este trabalho estatistico de importancia capital para nos precaver contra o excesso de profissionaes em um unico ramo de actividade. E' a bussola que deve guiar o governo nas directrizes a dar aos estudos dos jovens que se preparem para a lucta pela existencia e em proveito da patria. Cautelosos são os norte americanos neste particular, e, nos Estados Unidos do Norte, ha summa cautela e escrupulo no preparo destes quadros, sem os quaes só por palpite póde operar a administração publica. Pareceme que, no Brasil, sem embargo da falta de estatisticas officiaes, se pode dizer que o excesso de bachareis em Direito é um facto innegavel. Basta attentar no numero de Faculdades autorizadas á expedição de diplomas a letrados na arte juridica e ao de bachareis que a Ordem inscreve constantemente, para se poder, sem medo de erro, affirmar que é excessivo, não só o numero de advogados, mas tambem, esmando os que vão parà outros ramos de serviços (varias funcções publicas, magistratura, magisterio, etc.), que é demais a concurrencia em todos os outros logares buscados para ganhar o pão quotidiano pelos bachareis em Direito. Pouco tempo faz que um advogado desta capital negou seu apoio á aposentação de seus collegas sob funda- 
mento de que, sendo a classe muito rica, e capaz de soccorrer aos necessitados feridos da edade ou da molestia, inutil era a instituição. Acredito que são os advogados ricos nesta capital, centro de um Estado opulentissimo. Mas dar-se-á isto tambem nos outros Estados? Como é sabido, nos paizes estrangeiros orçam-se em $20 \%$ os que medram na profissão de que é patrono Santo Ivo. Si houver augmento de numero de advogados, a consequencia logica será que essa percentagem nos proventos diminuirá.

II - Logo que se põe em evidencia o grave problema, surge o remedio empirico: restringir o numero das matriculas nas escolas autorizadas ao fornecimento de cartas aos moços que almejam terçar armas no fôro. Nada mais absurdo, como fez sentir o notavel professor Alfredo PALAcios. Será destruir o que está feito, sem substituir o antigo por qualquer coisa melhor. Em sua Sociologia, diz Comte: “Un système ne peut s'éteindre qu'autant qu'un autre existe déjà tout formé, et prêt à le remplacer immédiatement". Sim: é muito do gosto dos administradores destruir em vez de construir, porque isto é, sem dúvida, mais difficil do que aquillo. Desde 1907, bato-me por uma solução mais racional, e vem a ser de incumbir-se o Estado de educação propria para as profissões, educação que habilite o moço a ganhar a subsistencia num ramo de actividade util á sociedade em que vae trabalhar. E' velhissimo o caso referido por Cervantes em seu D. Quixote, qual o do moço que era habilidosissimo, e que, contrahindo casamento, foi aconselhado pelo heróe do romance a ver si dava a seu talento uma direcção util á futura familia de que ia ser o chefe.

Sendo tão curta nossa vida, não mais é admissivel a doutrina antiga, segundo a qual um homem poderia ter uma educação geral, e, depois de sahir da escola, aprender um officio para ganhar a vida. Alem da perda de tempo, ha o inconveniente de ser o melhor processo para formar sarrafaçaes nas artes uteis ao Estado. E' a este que cumpre, para interesse da sociedade, ter constantemente cuidado 
em formar bons artifices. E, si não pode occupar-se em melhorar a industria do paiz, sendo o mais recommendavel dos processos o que adoptou CoLBERT, isto é, introducção de grandes mestres no paiz, deve, ao menos, fornecer serviço a todos. Não se diga que a machina veio inutilizar o trabalho manual do mestre, do operario, do artesano. Por mais desenvolvido que esteja o trabalho por machinas, sempre resta muito para a mão do individuo, que terá de manejar taes machinas, já de guerra, já industriaes.

Darei exemplo tirado dos Estados Unidos, a terra da padronização, da standartização, onde o individuo é, quanto possivel, absorvido pela machina. Lembra EDWARd EvereTt Hale que, ao tempo de George Washington, era este obrigado, quando dava uma ordem a seus officiaes, a explicar o modo por que deveriam executal-a, tal era a ignorancia destes na arte bellica (a "disciplina militar prestante", como disse o nosso epico), de modo que suas instrucções hoje poderiam até constituir um compendio da Arte Militar "a compendium or hand book of the Military Art". Prosegue dizendo que um bacharel em letras é ainda hoje obrigado a saber como sellar ou ferrar um cavallo, remar uma canoa, encadernar um livro, escolher um typo para impressão, etc.

Ora no Brasil os sarrafaçaes incumbem-se de concertar um automovel cuja machina não conhecem, um radio que pela primeira vez lhes é apresentado, e mesmo de outros apparelhos de que, embora de feitura antiga, elles não entendem por falta de educação technica. Nas mais insignificantes coisas, mostram os nossos denominados technicos a mais charra ignorancia. Na propria agricultura, neste paiz essencialmente agricola, fóra algum raro jardineiro, quem sabe os segredos da cultura da terra?

Mas eis que descambo para o aperfeiçoamento da educação, quando meu fim é só mostrar que o Estado é obrigado a fornecer este minimo indispensavel para o individuo ganhar a subsistencia. E' certo que o progresso na educação para uma profissão dá forças ao individuo para 
a lucta pela existencia. Neste artigo porém eu não me refiro áquelles para quem foi dicto que "There is always room higher up" Estes fazem-se, estes sacrificam-se, de modo a alcançarem os conhecimentos necessarios para obtenção dos meios de vida. Eu me refiro á figura média, ao homem mediocre, que é justamente aquelle a quem o Estado deve soccorrer.

III - Quando se falava no direito ao trabalho, ha uns annos passados, logo vinham os reaccionarios dizendo que era impossivel dar-se ao Estado a missão de fornecer clientes aos medicos ineptos e advogados ignorantes. Este despauterio foi passando de moda muito lentamente, e só com um decurso longuissimo de tempo chegou a Constituição de Novembro de 1937 a proclamar, de modo positivo, a existencia de um tal direito. 0 art. 136 , no $2 .^{\circ}$ membro, é claro demais para ser posto em dúvida o dever que o Estado assumiu de dar trabalho a todos quantos queiram applicar sua actividade em ganho honesto. 0 que se quer, quando se diz que o Estado é obrigado a dar serviço aos que não o alcançam por serem menos favorecidos pela natureza, é precisamente que a organização do trabalho seja tal que ainda estes mesmos possam subsistir com seus esforços. Só os vadios, só os que não querem applicar-se em serviço proveitoso aos seus e ao Estado devem ser castigados, como sendo ociosos merecedores da animadversão social.

Anteriormente, em várias memorias, indiquei como sendo os mais necessarios estudos em nosso paiz a Chimica Industrial e a Electricidade. Nosso paiz é pobre, disse Eduardo Prado, e foi amaldiçoado como estando a desacreditar a patria. E' um paiz rico potencialmente, disse o actual governo, querendo significar que tem campo a ser explorado pelo esforço do individuo. Sim: é impossivel encontrar logar onde mais se accentúe a maldição biblica de ganhar o homem o pão com o suór de seu rosto do que neste terrivel logar onde, no dizer de Euclydes da Cunha, a tenpa ainda não estava preparada para receber e hospedar 
o homem, natureza selvagem, embora remunerando o trabalho, quando feito mesmo com sacrificio da saúde. Com as quédas de agua de que dispomos, a electricidade será o meio seguro de obter calor, força e luz para todos os misteres da vida. Comquanto sujeita á congelação de suas quédas de agua, já soube a Noruega, muito antes de nós, as utilizar, supprindo pela hulha branca a falta de combustivel, a deficiencia do carvão.

Quando, no Brasil, se desenvolver o aproveitamento das quédas magnificas que possue a região, quando houver, em maior numero, estabelecimentos de producção de electricidade ou usinas electricas, como se diz geralmente, todos os serviços, mesmo os domesticos, serão feitos pelos apparelhos accionados pela força electrica. Desde a machina de costura até o automovel, tudo se fará por esta força. Pinturescamente descreve Ramalho Ortigão o papel que representa o moinho de vento na Hollanda, onde as correntes aéreas são a principal força motriz. E' o trabalhador infatigavel que dá o repouso ao braço humano. Communicando-lhe o escriptor vida, assemelhando-o a uma creatura humana, eis as proprias palavras do grande estylista: "Empregam-se em toda especie de misteres. Estes são simples moleiros, na accepção primitiva da palavra: moem milho ou moem cevada. Aquelles são lagareiros, e espremem as plantas oleaginosas de que se extraem os oleos industriaes e os oleos comestiveis dos Paizes Baixos. Ha-os carpinteiros, ha-os droguistas, ha-os cordoeiros; serram pranchas, racham lenha, cardam linho, torcem cordas, moem tintas. "(Hollanda, pag. $100,6 .^{a}$ edição), e por ahi vae uma enumeração que omittirei por não ter opportunidade em tão pequeno artigo como é este. No Brasil, por emquanto, a electricidade só tem sido applicada para aquecer as casas, illuminal-as, transmittir e receber recados no telephone, trazer noticias no radio. Si porém este prodigioso e mysterioso auxiliar do homem fôr desenvolvido, quanto machinismo será objecto de fabrico e concerto e portanto exigirá a acção dos technicos! Hoje é phrase corrente que, "quando um appa- 
relho, por mui‘o simples que seja, se desarranja, o remedio é atiral-o fóra, e comprar outro". Não ha quem saiba reparar um desarranjo causado pelo uso em um relogio mesmo, que é dos mais antigos machinismos, dentre os de uso domestico.

Nas industrias em que têm tentado fortuna sempre se arruinaram os bachareis em Direito. E' que perderam um tempo precioso a estudar o latim e o grego, em vez de conhecerem os segredos das artes uteis á vida e as regras de administração de estabelecimentos industriaes.

Permittam-me a narrativa de um facto de que fui testemunha auricular. Indo eu a certo estabelecimento commercial comprar massa para alimentação, disse-me o negociante que tinha superglutinada e hyperglutinada. Que differença ha entre as duas, perguntei para saber como escolher. A resposta não me esclareceu, mas calei-me. Um bacharel, que ia em minha companhia, acudiu, explicando que entre super e hyper a unica differença era ser um vocabulo grego e outro latino, tendo ambos a mesma significação, e ajuntou que o fabricante não sabia nem grego, nem latim, donde esta sua absurda prefixação. Sim, tornou o negociante, empregado do fabricante na casa commercial, meu patrão não sabe, nem grego, nem latim, mas sabe fazer macarrão, e o senhor, que sabe grego e latim, não sabe fazer macarrão.

IV - Si porém hoje não tem necessidade do amparo do Estado quem conhece electricidade, é fóra de duvida que o mesmo não se dá com a Chimica. Cumpre ao Estado prometter aos moços que obrigará os estabelecimentos industriaes, onde ha necessidade de conhecimentos technicos de Chimica, a terem empregados chefes que sejam formados pelas escolas officiaes nas quaes se dão os conhecimentos minimos indispensaveis para boa producção. Neste ramo do saber humano, a Alemanha supera a todos os outros paizes do mundo, já pela perfeição de seus productos, jálpela economia ou pelo aproveitamento da materia prima. 
Acabo de lêr um interessante artigo norte americano intitulado "Thank you, Hitler", onde o autor agradece a Hitler os sabios que este expulsou da Allemanha, e que foram estabelecer-se nos Estados Unidos do Norte (Readers Digest, Feb. 1938, pag. 81). Não seria caso de pensar em attrahir da Alemanha mestres não pertencentes á raça aryana, e que houvessem concorrido para a grandeza della, tendo agora ordem de emigrarem desse paiz adeantadissimo em tantos ramos de saber e particularmente na Chimica? Com facilidade conseguiriamos o que obteve Colbert em relação á Italia, naquella epocha, comquanto não houvesse expulsão dos artesanos da patria de DANTE. Quantas vantagens lhes daria o ministro de LuIz XIV para os seduzir de modo a deixarem a patria e irem estabelecer-se em França!

Incidentemente, seja-me facultado lembrar a importante verdade proclamada por tantos mestres de que um homem de talento e cultura significa para um paiz um valor economico, these que se comprovou quando Portugal expulsou para a Hollanda seus grandes homens, dentre os quaes se destacava Spinoza. Quando, em 1848, a revolução em França proclamou que não se deveria admittir a pena de morte em materias politicas, parece que teve em vista principalmente a perda dos grandes homens do paiz por momentanea exaltação politica. Si foi condemnado á morte LAvoisier por crime commum, força é reconhecer que a paixão politica influiu para essa perda soffrida pela França. Si Floriano Peixoto houvesse conseguido prender Ruy Barbosa, Eduardo Prado, Hilario de Gouveia, Ramiz Galvão, Rafael Corrêa da Silva, Luiz Philippe Baeta Neves e tantos outros valores patrios, seguramente tel-os-ia mandado matar, como disse clara e positivamente quando pelo Almirante Castil ho foi concedido asylo aos revoltosos nos navios portuguezes.

$\mathrm{V}$ - Parece que é ainda muito defeituoso o ensino nos Estados Unidos quando encarado por esse prisina. Mas noto a lucta que se trava naquelle paiz, tão cuidadoso em corrigir seus menores erros, para que tenha um caracter proveitoso tudo quanto se ensina nas escolas e universidades. 
Faz pouco tempo, no fasciculo de Dezembro de 1936 do Readers Digest, encontrei uma notícia sobre o destino que tiveram os 541 alumnos mais distinctos da Universidade de Harvard, notícia alcançada por um inquerito feito 25 annos após sua formatura. O resultado foi desanimador, e provou que o collegio pouco tinha feito com suas lições pelos 541 discipulos (pag. 57). Uma differença porém ha entre o povo do Norte e o brasileiro, e é que lá se procura corrigir o mal, e aqui apedreja-se o innovador, como succedeu commigo na Faculdade de Direito, quando dei notícia do perigo ha 30 annos. Tudo continuou como dantes, e só se pensou em restringir as matriculas nas escolas destinadas aos estudos destinados ás profissões liberaes.

Tempo é já de adoptar, ou a medida de desenvolver a educação profissional de assumptos uteis ao desenvolvimento economico ou da riqueza do Brasil, ou outra qualquer, tendo sempre deante dos olhos a pergunta classica dos anglo saxões: "Que emprego dar ao estudo feito na escola, que proveito tirar delle na vida, afim de ganhar o pão quotidiano e para proveito da patria"?

Education for business - What will he do with it são expressões que se encontram sempre em todos os estudos e investigações sobre o ensino a dar á mocidade na America do Norte. Acceitemos esta lição dos nossos irmãos do Norte, em vez de nos limitarmos a importar suas detestaveis musicas de fox trot e suas fitas cinematographicas pueris, ridiculas ou desmoralizadoras. 